\title{
In-hospital outcome of re-attempted percutaneous coronary interventions for chronic total occlusion
}

\author{
Jan-Erik Guelker ${ }^{1,3 *}$, Christian Blockhaus ${ }^{2,3 *}$, Alexander Bufe ${ }^{2,3}$, \\ Knut Kroeger ${ }^{4}$, Julian Kürvers ${ }^{2}$, Dimitrios Ilousis ${ }^{2}$, Kambis Mashayekhi ${ }^{5}$ \\ ${ }^{1}$ Department of Cardiology, Petrus Hospital, Wuppertal, Germany \\ ${ }^{2}$ Department of Cardiology, Heart Center Niederrhein, Helios Clinic, Krefeld, Germany \\ ${ }^{3}$ University Witten/Herdecke, Faculty of Health, Witten, Germany \\ ${ }^{4}$ Department of Angiology, Helios Clinic, Krefeld, Germany \\ ${ }^{5}$ Division of Cardiology and Angiology II, University Heart Center \\ Freiburg/Bad Krozingen, Bad Krozingen, Germany
}

\begin{abstract}
Background: With the advent of novel recanalization techniques and emerging devices, percutaneous coronary intervention (PCI) has become a promising leading treatment option for patients with chronic total occlusions (CTO). The present study aims to evaluate the acute outcomes of PCI in previously failed re-attempted vs. first-attempted CTO-lesions.

Methods: Between 2012 and 2019, 619 patients were included and treated with PCI of at least one CTO. 253 patients were re-attempted lesions, while 366 were initially attempted lesions.

Results: Re-attempted lesions were more complex, including higher Japanese-CTO (J-CTO) score and the need for a retrograde approach. The procedure time and fluoroscopy time were longer in this group. Nevertheless, overall success rates were comparable between both groups of patients. In-hospital events were rare and without significant differences.

Conclusions: Re-attempted CTO lesions are more complex than first-attempt lesions and are associated with longer procedural times. However, they can be safely intervened by experienced operators with a similar success rate. (Cardiol J 2023; 30, 1: 44-50)
\end{abstract}

Key words: re-attempt, chronic total occlusion, coronary artery disease, percutaneous coronary intervention

\section{Introduction}

Recanalization of chronic total occlusion (CTO) still remains a challenging procedure in interventional cardiology. A CTO of a coronary artery can be identified in up to $18 \%$ among patients referred for coronary angiography [1]. With the advent of novel recanalization techniques and emerging devices, percutaneous coronary intervention $(\mathrm{PCI})$ has become a promising leading treatment option for these patients [2-7].

Previous observational studies have demonstrated that successful CTO-PCI is associated with a better outcome in terms of reduced mortality and major adverse cardiac events (MACE) compared with CTO-PCI failure [8-11]. Several scores are currently used to estimate the procedural complexity of a CTO, but the Japanese-CTO (J-CTO)

Address for correspondence: Jan-Erik Guelker, MD, Petrus Hospital, Department of Cardiology, Wuppertal, Germany, University Witten/Herdecke, Faculty of Health, Witten, Germany, tel: 0049-202-299-2360, fax: 0049-202-299-2369, e-mail: janguelker14@gmail.com

Received: 4.01.2021 Accepted: 27.01.2021 Early publication date: 5.02.2021

This article is available in open access under Creative Common Attribution-Non-Commercial-No Derivatives 4.0 International (CC BY-NC-ND 4.0) license, allowing to download articles and share them with others as long as they credit the authors and the publisher, but without permission to change them in any way or use them commercially. 
score is still the most widely used [12-14]. J-CTO identifies a prior CTO-PCI failure as one of the five determinants to estimate the procedural complexity of a CTO-PCI. A considerable number of patients with failed CTO-PCI attempt are medically managed, instead of re-attempting the PCI [15]. The current literature provides only limited data about this challenging patient subgroup.

The present study aims to compare the acute outcomes of re-attempted CTO-PCI vs. first-attempt CTO-PCI.

\section{Methods}

The present study was designed as an observational retrospective study, including patients undergoing CTO-PCI in an experienced German CTO center between 2012 and 2019. The indication for CTO-PCI was based on current recommendations requiring the presence of clinical symptoms, including angina, dyspnea or limited exercise capacity [16-18]. Myocardial viability was proven either by evidence of normal wall motion or hypokinesia in the CTO territory, assessed by transthoracic echocardiography. In the presence of akinesia in the CTO-territory, positive functional ischemia/ /viability was proven by stress-echocardiography or cardiac magnetic resonance imaging (cMRI).

All procedures were performed via bifemoral approach using 7-French guiding catheters. Contra-lateral contrast injections were performed to determine the length of the CTO lesion and the existence and extent of collateral connections in the majority of patients. The decision to treat patients either by antegrade or retrograde CTO-PCI techniques was left to the operators' discretion. To prevent thromboembolic complications, heparin was intravenously administered during CTO-PCI, guided by regular measurements of the activated clotting time ( $>300 \mathrm{~s}$ ).

The J-CTO score, including the degree of calcification of the lesion, bending $>45^{\circ}$ in the CTO segment or at the entry, blunt proximal cap, length of occluded segment ( $>20 \mathrm{~mm}$ ) and a previously failed recanalization attempt, was calculated for all patients. The study was performed in accordance with the Declaration of Helsinki.

After CTO-PCI a dual antiplatelet therapy consisting of $100 \mathrm{mg}$ of acetylsalicylic acid once daily indefinitely and $75 \mathrm{mg}$ of clopidogrel once daily for at least 6 months was administered. Angiographic success was defined as a successful recanalization of the CTO with a residual stenosis less than
$30 \%$ and restoration of thrombolysis in myocardial infarction (TIMI)-flow grade 3 .

A composite safety endpoint combining inhospital death, vascular complications, cardiac tamponade, periprocedural infarction and an acute stent thrombosis was evaluated for every patient.

\section{Statistical analysis}

Continuous variables are presented as mean standard deviation, median (Q1-Q3) or as minimum to maximum range. Categorical variables are presented as absolute and relative frequencies. Normality of the variables was tested with the Shapiro-Wilk test. Continuous variables were compared with the Student t-test for unpaired samples, or with the Mann-Whitney U-test if a Gaussian distribution could not be assumed. For comparison of continuous variables among $>$ two categories were performed with non-parametric Kruskal-Wallis test. Categorical variables were compared using the Fisher exact test. According to the exploratory character of the analysis all $p$ values were interpreted as descriptive measures rather than as definitive inferential measures. A p-value of less than 0.05 was considered statistically significant, $\mathrm{p}<0.10$ was considered as a statistical trend.

\section{Results}

A total of 619 patients were included between 2012 and 2019. 253 (40.9\%) patients were reattempted lesions that had failed once previously, while $366(59.1 \%)$ were initially attempted lesions.

The majority of the patients were male (82.4\%) and the mean age was $62.0 \pm 10.3$ years. Male patients were younger than women $(61.1 \pm 10.1$ years vs. $66.3 \pm 10.1$ years; $p<0.005)$.

Table 1 presents the baseline clinical characteristics of the study patients. The major cardiovascular risk factors were similar between both groups, such as diabetes mellitus, hypertension and dyslipidemia. Furthermore, the rates of comorbidities like peripheral artery disease were comparable as well. Patients with a re-attempted lesion were less likely to have chronic obstructive pulmonary disease $(7.1 \%$ vs. $11.7 \%$; statistical trend $\mathrm{p}=0.074)$ and more often had an ejection fraction of more than $40 \%$ (97.2\% vs. $94.0 \%$; statistical trend $\mathrm{p}=0.080$ ). Interestingly the target vessel in these patients was mostly the right coronary artery (RCA; 65.2\%), followed by the left anterior descending artery (LAD; 20.6\%) and the left circumflex artery (LCX; 
Table 1. Baseline characteristics.

\begin{tabular}{|c|c|c|c|}
\hline & Initial attempt $(n=366)$ & Re-attempt (n = 253) & $\mathbf{P}$ \\
\hline Age [years] ${ }^{*}$ & $62(37-86)$ & $61(33-87)$ & 0.114 \\
\hline Hypertension & $81.4 \%(298)$ & $81.4 \%(206)$ & 1 \\
\hline Diabetes & $27.3 \%(100)$ & $24.1 \%(61)$ & 0.402 \\
\hline Male gender & $83.6 \%(306)$ & $80.6 \%(204)$ & 0.391 \\
\hline Smoking & $44.8 \%(164)$ & $47.8 \%(121)$ & 0.462 \\
\hline COPD & $11.7 \%(43)$ & $7.1 \%(18)$ & 0.074 \\
\hline Body mass index* & $27.5(18.0-46.7)$ & $27.4(17.0-45.0)$ & 0.604 \\
\hline Total cholesterol > $200 \mathrm{mg} / \mathrm{dL}$ & $21.2 \%(49)$ & $17.9 \%(35)$ & 0.464 \\
\hline LDL cholesterol > 100 mg/dL & $48.5 \%(112)$ & $47.7 \%(93)$ & 0.923 \\
\hline HDL cholesterol > $40 \mathrm{mg} / \mathrm{dL}$ & $68.0 \%(157)$ & $67.7 \%(132)$ & 1 \\
\hline Triglycerides > $150 \mathrm{mg} / \mathrm{dL}$ & $45.9 \%(106)$ & $48.2 \%(94)$ & 0.697 \\
\hline Peripheral artery disease & $12.0 \%(44)$ & $12.3 \%(31)$ & 1 \\
\hline Family liability for CAD & $28.1 \%(103)$ & $26.1 \%(66)$ & 0.583 \\
\hline Prior MI & $30.9 \%(113)$ & $37.5 \%(95)$ & 0.100 \\
\hline Prior CABG & $9.6 \%(35)$ & $9.1 \%(23)$ & 0.889 \\
\hline Prior PCl & $47.3 \%(238)$ & $43.5 \%(32)$ & 0.367 \\
\hline Ejection fraction $\geq 40 \%$ & $94.0 \%(505)$ & $97.2 \%(66)$ & 0.080 \\
\hline Multivessel disease & $79.0 \%(289)$ & $67.9 \%(172)$ & 0.003 \\
\hline CTO location: & & & 0.003 \\
\hline LAD & $32.5 \%(119)$ & $20.6 \%(52)$ & \\
\hline LCX & $10.9 \%(40)$ & $14.2 \%(36)$ & \\
\hline $\mathrm{RCA}$ & $54.9 \%(201)$ & $65.2 \%(165)$ & \\
\hline
\end{tabular}

* Median (min-max); CABG - coronary artery bypass grafting; CAD - coronary artery disease; COPD — chronic obstructive pulmonary disease; CTO — chronic total occlusion; HDL — high density lipoprotein; LAD — left anterior descending; LDL — low density lipoprotein; $\mathrm{LCX}$ - left circumflex; $\mathrm{MI}$ - myocardial infarction; $\mathrm{PCl}$ - percutaneous coronary intervention; RCA — right coronary artery

14.2\%). Patients with an initially attempted lesion had a different distribution (RCA: $54.9 \%$, LAD: $32.5 \%$, LCX: $10.9 \%$; $p=0.003)$ and more often a multivessel coronary artery disease $(79.0 \%$ vs. $67.9 \% ; \mathrm{p}=0.005)$. The success $(\mathrm{p}=1.000)$ and complication rates $(\mathrm{p}=0.385)$ were independent of the target vessel.

Peri-procedural characteristics are demonstrated in Table 2. Patients with a re-attempted lesion had more often a blunt stump morphology $(70.0 \%$ vs. $58.2 \%, \mathrm{p}=0.003)$ and a higher J-CTO score (62.5\% vs. $18.6 \%, \mathrm{p} \leq 0.001$; Fig. 1$)$. It was also determined that examination and fluoroscopy time were longer in this group ( $120 \mathrm{~min}$ vs. $90 \mathrm{~min}$, $\mathrm{p}<0.001$ and 37 min vs. $28 \mathrm{~min}, \mathrm{p}<0.001$; Fig. 2) and that in this group of patients the retrograde approach was more frequently used (32.4\% vs. $12.0 \%$, $\mathrm{p}<0.001)$. Patients with an initially attempted lesion were less likely to have an ostial lesion $(8.7 \%$ vs. $14.2 \%, \mathrm{p}=0.036)$ and showed rarely an in-stent CTO (6.3\% vs. $18.2 \%$, p < 0.001).
The most frequent reason for failure in reattempted CTO lesions was the failure of the guidewire to cross the lesion. No procedure was discontinued due to complications.

Overall success rates were comparable between the two group of patients $(86.9 \%$ vs. $83.0 \%$, $\mathrm{p}=0.204)$.

Reverse controlled antegrade and retrograde tracking and parallel-wire techniques were more frequently used in re-attempted than in firstattempt lesions $(67.1 \%$ vs. $41 \%, \mathrm{p}<0.001$ and $24.4 \%$ vs. $8.9 \%, \mathrm{p}<0.001$, respectively).

In-hospital, acute procedural complications regarding the composite safety endpoint were rare and showed no significant difference $(6.0 \%$ vs. $4.0 \%, \mathrm{p}=0.467)$. They included mostly vascular complications $(\mathrm{n}=26)$ such as a local hematoma at the puncture site and could be treated without further consequences. No severe complications such as peri-procedural death, ST-segment elevation myocardial infarction occurred (Table 3 ). 
Table 2. Procedural and angiographic characteristics.

\begin{tabular}{|c|c|c|c|}
\hline & Initial attempt $(n=366)$ & Re-attempt (n = 253) & $\mathbf{P}$ \\
\hline Complication rate & $6.0 \%(22)$ & $4.0 \%(11)$ & 0.467 \\
\hline Success rate & $86.9 \%(318)$ & $83.0 \%(210)$ & 0.204 \\
\hline Calcification & $65.6 \%(240)$ & $77.5 \%(196)$ & 0.002 \\
\hline Length of lesion [mm] ${ }^{*}$ & $30(10-100)$ & $30(10-79)$ & 0.240 \\
\hline In-stent CTO & $6.3 \%(23)$ & $18.2 \%(46)$ & $<0.001$ \\
\hline Blunt stump & $58.2 \%(213)$ & $70.0 \%(177)$ & 0.003 \\
\hline Ostial CTO & $8.7 \%(32)$ & $14.2 \%(36)$ & 0.036 \\
\hline J-CTO score $>3$ & $18.6 \%(68)$ & $62.5 \%(158)$ & $<0.001$ \\
\hline Retrograde technique & $12.0 \%(44)$ & $32.4 \%(82)$ & $<0.001$ \\
\hline Stent type: & & & 0.686 \\
\hline DES & $99.1 \%(457)$ & $98.6 \%(47)$ & \\
\hline BMS & $0.9 \%(3)$ & $1.4 \%(3)$ & \\
\hline Diameter of stent $[\mathrm{mm}]^{*}$ & $3.0(2.25-4.0)$ & $3.0(2.5--4.0)$ & 0.332 \\
\hline Lenght of stent [mm] ${ }^{*}$ & $62(12-157)$ & $64(18-170)$ & 0.955 \\
\hline Number of stents* & $2(0-6)$ & $2(0-6)$ & 0.490 \\
\hline Amount of contrast medium $[\mathrm{mL}]^{*}$ & $200(70-750)$ & $200(80-800)$ & 0.161 \\
\hline Fluoroscopy time [min] ${ }^{*}$ & $28(4-113)$ & $37(7-104)$ & $<0.001$ \\
\hline Examination time [min] ${ }^{*}$ & $90(11-208)$ & $120(20-300)$ & $<0.001$ \\
\hline
\end{tabular}

${ }^{*}$ Median (min-max), BMS — bare metal stent; CTO — chronic total occlusion; DES — drug eluting stent; J-CTO — Japanese CTO

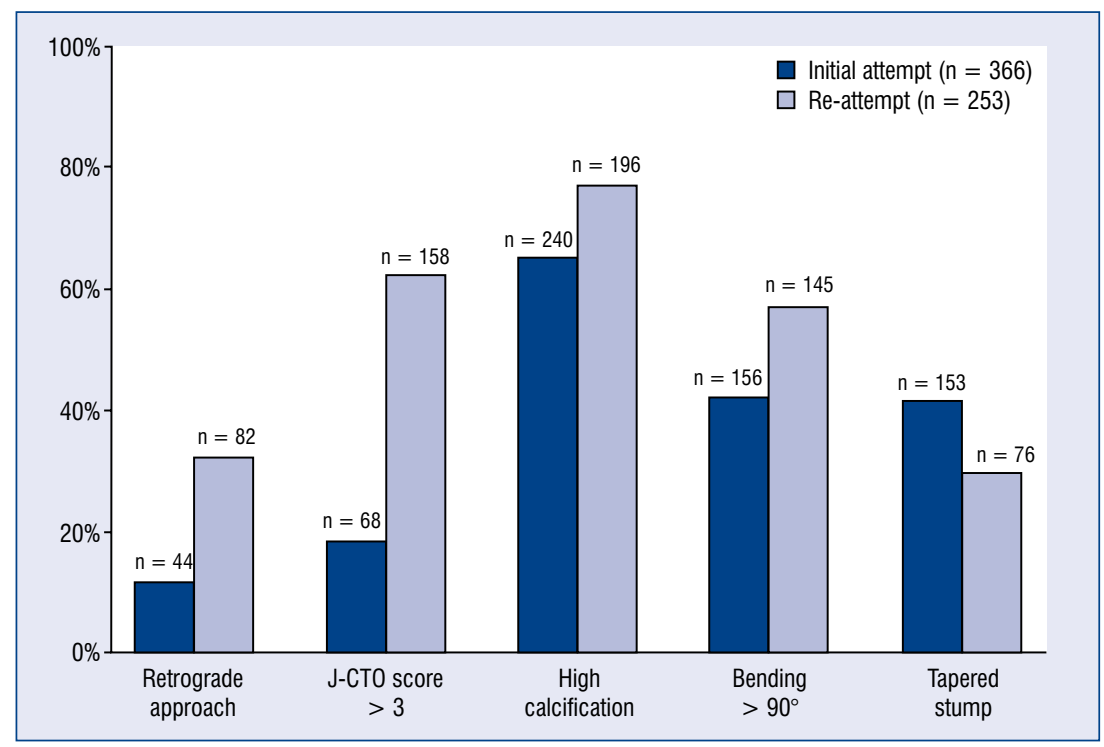

Figure 1. Various parameters of initial attempted and re-attempted chronic total occlusion percutaneous coronary intervention reflecting the complexity of the lesions.

Patients without a successful recanalization in a second attempt were treated medically in $69 \%$, whilst $31 \%$ underwent coronary artery bypass grafting (CABG).

\section{Discussion}

According to available research itis known that an incomplete revascularization is accompanied by 


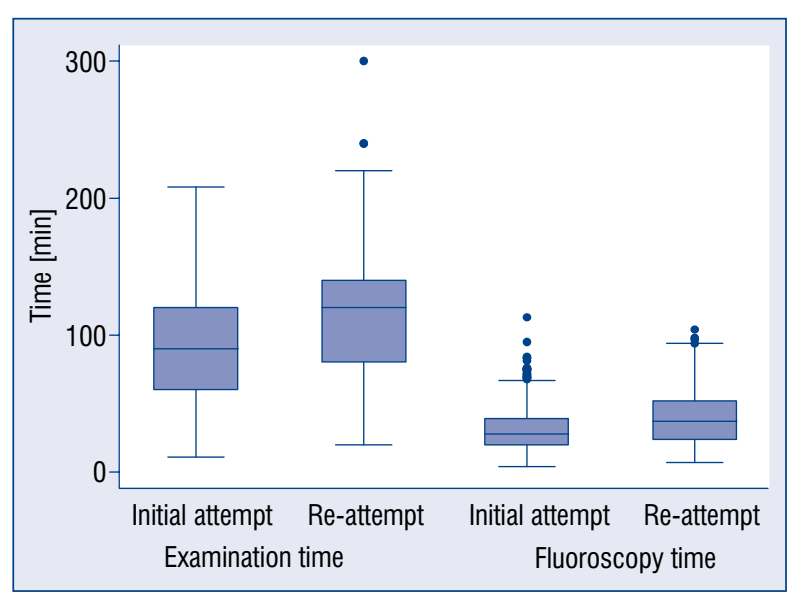

Figure 2. Comparison of initial attempted and re-attempted chronic total occlusion percutaneous coronary intervention regarding examination and fluoroscopy time.

Table 3. In-hospital events.

\begin{tabular}{lcc}
\hline & $\begin{array}{c}\text { Initial } \\
\text { attempt } \\
\text { (n=366) }\end{array}$ & $\begin{array}{c}\text { Re- } \\
\text {-attempt } \\
\text { (n= 253) }\end{array}$ \\
\hline In-hospital death & 0 & 0 \\
Vascular complications & 17 & 9 \\
Cardiac tamponade & 4 & 0 \\
Stroke & 1 & 0 \\
Myocardial infarction & 0 & 0 \\
\hline
\end{tabular}

increased adverse events $[19,20]$. Therefore, it should be a goal to perform a successful recanalization even after a failed CTO-PCI attempt.

In a large meta-analysis with more than 7000 patients, Joyal et al. [21] demonstrated that successful CTO-PCI compared to a failed attempt could show a reduction, not only in long-term mortality, but also the need for CABG. Furthermore, van der Schaaf et al. [22] showed that the presence of a non-revascularized CTO increases the long-term mortality in a case of acute myocardial infarction $[21,22]$. As is done nowadays, CTO-PCI can be performed in a safe and sufficient way by most CTO centers, the present study emphasizes several important aspects of CTO-PCI in re-attempted cases.

Firstly, the present study, in contrast to other studies, it was shown that recanalization of reattempted lesion can be performed with similar success and complication rates compared with first-attempt lesions [19]. This is the case, even though our data suggests a higher complexity in re-attempted lesions than in firs-attempt cases, as indicated by the higher J-CTO score. The fact that all cases in the study were performed by two highly-experienced CTO operators, might have also played an instrumental role in the excellent results reported.

Despite the fact that a re-attempt itself is counted as a point of complexity in the J-CTO score, it was determined that calcification, tortuosity and blunt stump morphology were significantly increased in patients with a re-attempt. These findings are in accordance with data from Tanabe et al. [19]. But, in that study only about 300 patients, 59 with a re-attempted lesion, were included and the success rate was much lower in the patients with re-attempted lesions $(69.5 \%)$ due to the fact that treatment devices failed to cross even after successful guidewire crossing. In a large Japanese CTO registry, more than 4000 patients were included and the technical success rate of re-attempt CTO-PCI was lower than that of first attempt CTO-PCI, but the mean age of this cohort was much older than in our study [23].

Second, re-attempted CTO lesions required complex interventional approaches, for instance the retrograde approach, with longer fluoroscopic and examination times. This finding is congruent to a large multicenter registry from 2015 which showed that the mean procedure duration was significantly longer in the group with prior failed CTO-PCI attempts (142 vs. $125 \mathrm{~min}, \mathrm{p}=0.026$ ), as was mean fluoroscopy time (55 vs. $45 \mathrm{~min}$, $\mathrm{p}=0.015)[24]$.

As shown by the large EURO CTO Club registry that the number of retrograde procedures has been continually increasing over recent years, based on the higher complexity of lesion subsets, giving us more technical options to increase the success rates in CTO-PCI, despite low rates of major complications, and good long-term outcome. This has recently been confirmed by the data of Tanaka et al. [25, 26]. Wei et al. [27] examined 2124 patients who received cardiac fluoroscopic interventions and found that a chronic skin ulcer developed in $0.34 \%$. Since then, there have been significant reductions in radiation doses over time by introducing new techniques and changes in fluoroscopy settings [27-30].

Third, re-attempted lesions are often in-stent lesions. This is in accordance with a large study by Karacsonyi et al. [24] comprising 1213 consecutive patients from 12 centers in the United States between 2012 and 2015. Interestingly, in contrast 
to the present study, this cohort the incidence of MACE was numerically higher among prior failed cases [24]. It should be pointed out that PCI for instent CTO might be associated with higher odds of MACE and myocardial infarction compared to PCI for de-novo CTO [31]. Finally, the current study demonstrated that RCA was the target vessel in both groups. Interestingly CTOs located in the $\mathrm{LAD}$ artery were more often treated in the setting of re-attempted PCI.

Since it is known that especially after a successful recanalization of the $\mathrm{LAD}$, ejection fraction and clinical outcome may improve [32-34], efforts should focus on revascularization of this vessel.

\section{Limitations of the study}

The present study is a retrospective analysis and all data are collected from a single center. The results of this study may have been influenced by selection criteria, bias on operator's experience, and varying techniques used by the two operators involved. Furthermore, no data about the impact of the long-term follow-up in this cohort is reported.

\section{Conclusions}

Percutaneous coronary intervention of reattempted CTO lesions are as safe as primary CTO attempts, with comparable success rates. PCI of re-attempted CTO lesions has shown higher anatomical complexity, requiring a more complex approach, including retrograde techniques and longer procedures times, for successful revascularization.

Conflict of interest: Jan-Erik Guelker received consulting/speaker honoraria from Bayer and Boeringer-Ingelheim; Christian Blockhaus: none; Alexander Bufe: none; Knut Kroeger: none; Julian Kürvers: none; Dimitrios Ilousis: none; Kambis Mashayekhi received consulting/speaker honoraria from Abbott Vascular, Asahi Intecc, Biotronik, Boston Scientific, Daiichi Sankyo, Nitiloop, Vascular Solution, Terumo.

\section{References}

1. Azzalini L, Jolicoeur EM, Pighi M, et al. Epidemiology, management strategies, and outcomes of patients with chronic total coronary occlusion. Am J Cardiol. 2016; 118(8): 1128-1135, doi: 10.1016/j.amjcard.2016.07.023, indexed in Pubmed: 27561190 .

2. Fefer P, Knudtson ML, Cheema AN, et al. Current perspectives on coronary chronic total occlusions: the Canadian Multicenter Chronic Total Occlusions Registry. J Am Coll Cardiol. 2012;
59(11): 991-997, doi: 10.1016/j.jacc.2011.12.007, indexed in Pubmed: 22402070.

3. Tomasello SD, Boukhris M, Giubilato S, et al. Management strategies in patients affected by chronic total occlusions: results from the Italian Registry of Chronic Total Occlusions. Eur Heart J. 2015; 36(45):3189-3198, doi: 10.1093/eurhearti/ehv450, indexed in Pubmed: 26333367.

4. Bufe A, Haltern G, Dinh W, et al. Recanalisation of coronary chronic total occlusions with new techniques including the retrograde approach via collaterals. Neth Heart J. 2011; 19(4): 162-167, doi: 10.1007/s12471-011-0091-7, indexed in Pubmed: 22020996.

5. Galassi AR, Tomasello SD, Reifart N, et al. In-hospital outcomes of percutaneous coronary intervention in patients with chronic total occlusion: insights from the ERCTO (European Registry of Chronic Total Occlusion) registry. EuroIntervention. 2011; 7(4): 472-479, doi: 10.4244/EIJV7I4A77, indexed in Pubmed: 21764666.

6. Christopoulos G, Menon RV, Karmpaliotis D, et al. The efficacy and safety of the „hybrid” approach to coronary chronic total occlusions: insights from a contemporary multicenter US registry and comparison with prior studies. J Invasive Cardiol. 2014; 26(9): 427-432, indexed in Pubmed: 25198485.

7. Galassi AR, Sianos G, Werner GS, et al. Retrograde recanalization of chronic total occlusions in europe: procedural, in-hospital, and long-term outcomes from the multicenter ERCTO registry. J Am Coll Cardiol. 2015; 65(22): 2388-2400, doi: 10.1016/j. jacc.2015.03.566, indexed in Pubmed: 26046732.

8. Alessandrino $\mathrm{G}$, Chevalier $\mathrm{B}$, Lefèvre $\mathrm{T}$, et al. A clinical and angiographic scoring system to predict the probability of successful first-attempt percutaneous coronary intervention in patients with total chronic coronary occlusion. JACC Cardiovasc Interv. 2015; 8(12): 1540-1548, doi: 10.1016/j.jcin.2015.07.009, indexed in Pubmed: 26493246.

9. Rathore S, Matsuo H, Terashima M, et al. Procedural and inhospital outcomes after percutaneous coronary intervention for chronic total occlusions of coronary arteries 2002 to 2008: impact of novel guidewire techniques. JACC Cardiovasc Interv. 2009; 2(6): 489-497, doi: 10.1016/j.jcin.2009.04.008, indexed in Pubmed: 19539251.

10. Michael TT, Karmpaliotis D, Brilakis ES, et al. Procedural outcomes of revascularization of chronic total occlusion of native coronary arteries (from a multicenter United States registry). Am J Cardiol. 2013; 112(4): 488-492, doi: 10.1016/j. amjcard.2013.04.008, indexed in Pubmed: 23672987.

11. Prasad A, Rihal CS, Lennon RJ, et al. Trends in outcomes after percutaneous coronary intervention for chronic total occlusions: a25-yearexperiencefrom the Mayo Clinic.JAm Coll Cardiol.2007; 49(15): 1611-1618, doi: 10.1016/j.jacc.2006.12.040, indexed in Pubmed: 17433951.

12. Cuevas C, Ryan N, Quirós A, et al. Determinants of percutaneous coronary intervention success in repeat chronic total occlusion procedures following an initial failed attempt. World J Cardiol. 2017; 9(4): 355-362, doi: 10.4330/wjc.v9.i4.355, indexed in Pubmed: 28515854.

13. Morino Y, Abe M, Morimoto T, et al. Predicting successful guidewire crossing through chronic total occlusion of native coronary lesions within 30 minutes: the J-CTO (Multicenter CTO Registry in Japan) score as a difficulty grading and time assessment tool. JACC Cardiovasc Interv. 2011; 4(2): 213-221, doi: 10.1016/j.jcin.2010.09.024, indexed in Pubmed: 21349461. 
14. Szijgyarto Z, Rampat R, Werner GS, et al. Derivation and validation of a chronic total coronary occlusion intervention procedural success score from the 20,000-patient EuroCTO registry: the EuroCTO (CASTLE) score. JACC Cardiovasc Interv. 2019; 12(4): 335-342, doi: 10.1016/j.jcin.2018.11.020, indexed in Pubmed: 30711551.

15. Syrseloudis D, Secco GG, Barrero EA, et al. Increase in J-CTO lesion complexity score explains the disparity between recanalisation success and evolution of chronic total occlusion strategies: insights from a single-centre 10-year experience. Heart. 2013; 99(7): 474-479, doi: 10.1136/heartjnl-2012-303205, indexed in Pubmed: 23376946.

16. Windecker S, Kolh P, Alfonso F, et al. 2014 ESC/EACTS Guidelines on myocardial revascularization: The Task Force on Myocardial Revascularization of the European Society of Cardiology (ESC) and the European Association for Cardio-Thoracic Surgery (EACTS)Developed with the special contribution of the European Association of Percutaneous Cardiovascular Interventions (EAPCI). Eur Heart J. 2014; 35(37): 2541-2619, doi: 10.1093/ eurheartj/ehu278, indexed in Pubmed: 25173339.

17. Levine G, Bates E, Blankenship J, et al. 2011 ACCF/AHA/SCAI Guideline for Percutaneous Coronary Intervention: a report of the American College of Cardiology Foundation/American Heart Association Task Force on Practice Guidelines and the Society for Cardiovascular Angiography and Interventions. Circulation. 2011; 124(23): e574-e651, doi: 10.1161/cir.0b013e31823ba622.

18. Azzalini L, Torregrossa G, Puskas JD, et al. Percutaneous revascularization of chronic total occlusions: Rationale, indications, techniques, and the cardiac surgeon's point of view. Int J Cardiol. 2017; 231: 90-96, doi: 10.1016/j.ijcard.2017.01.026, indexed in Pubmed: 28089148.

19. Tanabe M, Kodama K, Asada K, et al. Lesion characteristics and procedural outcomes of re-attempted percutaneous coronary interventions for chronic total occlusion. Heart Vessels. 2018; 33(6): 573-582, doi: 10.1007/s00380-017-1091-3, indexed in Pubmed: 29224054.

20. Hannan EL, Wu C, Walford G, et al. Incomplete revascularization in the era of drug-eluting stents: impact on adverse outcomes. JACC Cardiovasc Interv. 2009; 2(1): 17-25, doi: 10.1016/j. jcin.2008.08.021, indexed in Pubmed: 19463393.

21. Joyal D, Afilalo J, Rinfret S. Effectiveness of recanalization of chronic total occlusions: a systematic review and metaanalysis. Am Heart J. 2010; 160(1): 179-187, doi: 10.1016/j. ahj.2010.04.015, indexed in Pubmed: 20598990.

22. van der Schaaf RJ, Vis M, Sjauw K, et al. Impact of multivessel coronary disease on long-term mortality in patients with ST-elevation myocardial infarction is due to the presence of a chronic total occlusion. Am J Cardiol. 2006; 98(9): 1165-1169, doi: 10.1016/j.amjcard.2006.06.010.

23. Sekiguchi M, Muramatsu T, Kishi K, et al. Assessment of reattempted percutaneous coronary intervention strategy for chronic total occlusion after prior failed procedures: Analysis of the Japanese CTO-PCI Expert Registry. Catheter Cardiovasc Interv. 2019; 94(4): 516-524, doi: 10.1002/ccd.28315, indexed in Pubmed: 31062477.
24. Karacsonyi J, Karatasakis A, Karmpaliotis D, et al. Effect of previous failure on subsequent procedural outcomes of chronic total occlusion percutaneous coronary intervention (from a contemporary multicenter registry). Am J Cardiol. 2016; 117(8): 1267-1271, doi: 10.1016/j.amjcard.2016.01.021, indexed in Pubmed: 26899493.

25. Galassi AR, Sianos G, Werner GS, et al. Retrograde recanalization of chronic total occlusions in europe: procedural, in-hospital, and long-term outcomes from the multicenter ERCTO registry. J Am Coll Cardiol. 2015; 65(22): 2388-2400, doi: 10.1016/j. jacc.2015.03.566, indexed in Pubmed: 26046732.

26. Tanaka H, Ohya M, Kubo S, et al. Impact of retrograde approach on long-term clinical outcomes of patients undergoing coronary chronic total occlusion interventions. EuroIntervention. 2015; 14(11): e1183-e1191, doi: 10.4244/EIJ-D-18-00534, indexed in Pubmed: 30082257.

27. Wei KC, Yang KC, Mar GY, et al. STROBE - radiation ulcer: an overlooked complication of fluoroscopic intervention: a crosssectional study. Medicine (Baltimore). 2015; 94(48): e2178, doi: 10.1097/MD.0000000000002178, indexed in Pubmed: 26632903.

28. Werner GS, Glaser P, Coenen A, et al. Reduction of radiation exposure during complex interventions for chronic total coronary occlusions: Implementing low dose radiation protocols without affecting procedural success rates. Catheter Cardiovasc Interv. 2017; 89(6): 1005-1012, doi: 10.1002/ccd.26886, indexed in Pubmed: 28112448.

29. Shorrock D, Christopoulos G, Wosik J, et al. Impact of a disposable sterile radiation shield on operator radiation exposure during percutaneous coronary intervention of chronic total occlusions. J Invasive Cardiol. 2015; 27(7): 313-316, indexed in Pubmed: 26136277.

30. Tajti P, Brilakis ES. Chronic total occlusion percutaneous coronary intervention: evidence and controversies. J Am Heart Assoc. 2018; 7(2): e006732, doi: 10.1161/JAHA.117.006732, indexed in Pubmed: 29330258.

31. Mir T, Ullah W, Sattar Y, et al. Outcomes of percutaneous intervention in in-stent versus de-novo chronic total occlusion: a meta-analysis. Expert Rev Cardiovasc Ther. 2020; 18(11): 827-833, doi: 10.1080/14779072.2020.1813026, indexed in Pubmed: 32842807.

32. Tanabe M, Kodama K, Asada K, et al. Lesion characteristics and procedural outcomes of re-attempted percutaneous coronary interventions for chronic total occlusion. Heart Vessels. 2018; 33(6): 573-582, doi: 10.1007/s00380-017-1091-3, indexed in Pubmed: 29224054.

33. Safley DM, House JA, Marso SP, et al. Improvement in survival following successful percutaneous coronary intervention of coronary chronic total occlusions: variability by target vessel. JACC Cardiovasc Interv. 2008; 1(3): 295-302, doi: 10.1016/j. jcin.2008.05.004, indexed in Pubmed: 19463316.

34. Claessen BE, Dangas GD, Godino C, et al. Multinational CTO Registry. Impact of target vessel on long-term survival after percutaneous coronary intervention for chronic total occlusions. Catheter Cardiovasc Interv. 2013; 82(1): 76-82, doi: 10.1002/ ccd.24579, indexed in Pubmed: 22888007. 